\title{
On the potential of oncolytic virotherapy for the treatment of canine cancers
}

\author{
Amy L MacNeill \\ Department of Microbiology, \\ Immunology, and Pathology, College of \\ Veterinary Medicine and Biomedical \\ Sciences, Colorado State University, \\ Fort Collins, CO, USA
}

This article was published in the following Dove Press journal:

Oncolytic Virotherapy

26 August 2015

Number of times this article has been viewed

Correspondence: Amy L MacNeill Department of Microbiology, Immunology, and Pathology, College of Veterinary Medicine and Biomedical Sciences, Colorado State University, 300 W Drake Rd, Fort Collins, CO 80523-1644, USA

$\mathrm{Tel}+$ I 9702975 I I 2

Fax + I 970297444 I

Email amy.macneill@colostate.edu

\begin{abstract}
Over 6 million dogs are diagnosed with cancer in the USA each year. Treatment options for many of these patients are limited. It is important that the veterinary and scientific communities begin to explore novel treatment protocols for dogs with cancer. Oncolytic viral therapy is a promising treatment option that may prove to be relatively inexpensive and effective against several types of cancer. The efficacy of oncolytic virus therapies has been clearly demonstrated in murine cancer models, but the positive outcomes observed in mice are not always seen in human cancer patients. These therapies should be thoroughly evaluated in dogs with spontaneously arising cancers to provide needed information about the potential effectiveness of virus treatment for human cancers and to promote the health of our companion animals. This article provides a review of the results of oncolytic virus treatment of canine cancers.
\end{abstract}

Keywords: oncolytic virus, cancer, canine

\section{Introduction}

There is a growing interest in using viruses to eliminate cancers. There are many excellent articles that review the current use of oncolytic viruses in human clinical trials. ${ }^{1-4}$ Very recently, there have been enough positive results from human clinical trials that emerging oncolytic viral therapies have been showcased by popular media programs. A report by the Home Box Office (HBO) series Vice focused on trials using recombinant poxvirus, measles virus, and lentivirus to treat a variety of cancers. The Columbia Broadcasting System (CBS) news show 60 Minutes aired interviews with researchers and patients involved in trials using a modified poliovirus to treat patients with glioblastoma. Hopefully, this type of press will spur interest in funding additional oncolytic virus studies.

\section{One hundred and eleven years of viral cancer therapy}

The idea of using pathogens to eliminate neoplastic cells is not a new one. It began in the early 20th century with a report of remission of leukemia in a woman who had acquired a respiratory infection (likely influenza). ${ }^{5}$ In the 1950 s and 1960s, interest in oncolytic viruses reemerged, leading to some promising human clinical trials including the use of adenovirus to treat cervical carcinoma. ${ }^{6}$ However, during this time period, the ethics of how patients were recruited into clinical trials were highly questionable and oncolytic virus studies were stopped. Since then, ethical guidelines for human clinical trials have been established and there have been critical scientific advances in molecular biology, cancer biology, immunology, and pathogenesis of infectious diseases. These developments have enabled scientists to design recombinant viruses that are 
no longer pathogenic, but demonstrate improved targeting of neoplastic cells, enhanced oncolytic properties, and/or desirable immunologic effects. In 2005, People's Republic of China approved a conditionally replicating adenovirus for the treatment of human head and neck squamous cell carcinoma. $^{7}$ This oncolytic viral therapy may be beneficial, but its efficacy likely can be improved and additional types of cancers can be targeted.

Several clinical cancer trials are ongoing to evaluate the effectiveness of attenuated viruses in humans, but trials in canine cancer patients are rare. ${ }^{1,2,8,9}$ Genetically altered viruses currently being tested in humans include adenovirus, coxsackievirus, herpes simplex virus, lentivirus, measles virus, parvovirus, poliovirus, reovirus, retrovirus, and vaccinia virus (VACV). ${ }^{1,10}$ Newcastle disease virus, myxoma virus (MYXV), and others are actively being studied in murine cancer models. Unfortunately, many of the initial oncolytic viral therapies that were successful at clearing xenografts in murine tumor models failed to significantly induce remission in humans. This may be due to the fact that there are several aspects of spontaneous oncogenesis that cannot be replicated in murine tumor models. For example, the tumor microenvironment in a spontaneously arising neoplasm is very complex and involves modifications of the local vasculature and extracellular matrix that are not recapitulated in xenografts. Also, alterations in the immune system of cancer patients that allow for tumorigenesis to occur are not a component of murine xenograft models.

\section{The importance of clinical trials in dogs with cancer}

To continue to improve the efficacy of new cancer therapeutics, it is imperative that scientists begin to utilize cancer models which recapitulate the tumor microenvironment and the immunotolerance known to occur during oncogenesis. Spontaneous tumors of dogs are beginning to be recognized as an important model of human cancer that can meet these criteria. Additionally, dogs are outbred and their genetics are well classified, dogs and humans have similar exposure to environmental factors that affect tumorigenesis, and the biologic behavior of several canine cancers parallels the clinical disease course observed in humans. ${ }^{11,12}$ In the author's opinion, dogs with spontaneously arising cancers are an underutilized population of patients that are excellent animal models of human cancers and simultaneously could benefit from adjunctive treatment with an appropriate oncolytic virus. Just as data from canine clinical trials could improve responses to oncolytic viruses in human cancer patients, information learned from human clinical trials could be used to develop effective treatment protocols in canine cancer patients.

\section{Key attributes of viral cancer therapy}

Initially, it was thought that direct lysis of cancer cells by a virus would be the primary mechanism for the anticancer effects of a virus therapy, hence the term "oncolytic virus therapy". Although virus-induced cancer cell death does occur, there is a large amount of evidence that indicates the immune response to the virus is a key component of an effective anticancer virus therapy. ${ }^{10,13}$ The ideal oncolytic virus should destroy tumor cells throughout the body and induce antitumor immunity without damaging healthy cells. Indeed, safety is a key concern with oncolytic viruses, particularly when used in immunosuppressed patients. Safety may be enhanced by using nonpathogenic, genetically stable virotherapeutics derived from wild-type viruses that do not cause severe disease and lack the ability to integrate into the patients' DNA.

\section{Tumor specificity of oncolytic viruses}

Increasing the tumor specificity of a virotherapeutic also can enhance its safety. Interestingly, some of the common cellular pathway alterations found in neoplasms allow viruses to productively and selectively infect tumor cells (Figure 1). Several tumor cells have mutations in key components of intracellular signaling pathways which block apoptosis and/ or promote proliferation, making them susceptible to viral infection. Other tumor cells lack adequate antiviral interferon responses that prevent virus replication in noncancerous cells. Some viruses are inherently tumor-selective or can be genetically altered to improve tumor specificity. For example, in many oncolytic adenoviruses, the viral Ela gene is disrupted and/or the E1b-55K gene is deleted so that the viruses can only replicate in cells with defective retinoblastoma or p53 pathways, respectively. ${ }^{14}$ Also, several oncolytic VACVs have the viral thymidine kinase gene deleted, which limits virus replication to actively dividing cells. ${ }^{15,16}$ Additionally, oncolytic viruses may be designed to contain tumor-specific promoter elements that only permit replication of the virus in tumor cells.

\section{The immune response to virus therapy}

Oncolytic virotherapy has the potential benefit of altering the tumor microenvironment enough to break existing tumor immunotolerance (Figure 2). Failure of the immune system to recognize tumor cells may be due to a paucity of stimulated immune cells infiltrating the tumor and/or 


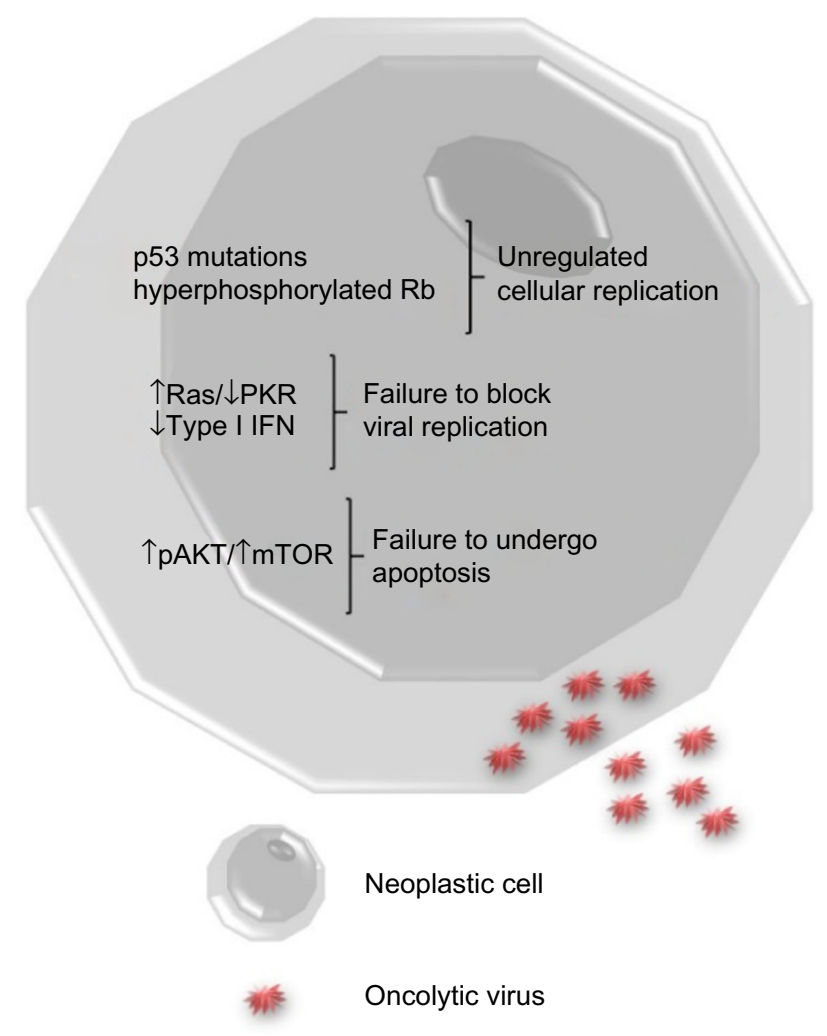

Figure I Tumor cell biology.

Notes: Neoplastic cells have alterations in cell signaling pathways that enable oncolytic viruses to infect them. Upon infection with a virus, healthy cells activate antiviral pathways (Ras/PKR) and produce type I interferons (IFNs) that prevent viral replication. This often does not occur in cancer cells. Many cancer cells have mutations in tumor suppressor genes such as $\mathrm{p} 53$ and retinoblastoma protein $(\mathrm{Rb})$ that promote cell proliferation and turn on cellular pathways that prevent cell death (pAKT/mTOR). Viruses are able to take advantage of the increased cell proliferation using cellular nucleotides and proteins involved in the cell cycle to promote replication of viral DNA/RNA, production of viral proteins, and release of larger numbers of mature virus particles.

masking of tumor antigens. Aberrant cytokine patterns in the tumor microenvironment may severely limit an antitumor immune response. ${ }^{17,18}$ Additionally, regulatory T-cells and myeloid-derived suppressor cells may be present in increased numbers in cancer patients. These immunologic hurdles can be overcome by oncolytic viral therapy if infected tumor cells express viral antigens that trigger a fully functional cellular immune response and alter cytokine production to promote infiltration of immune cells. Ideally, when the cellular immune response lyses infected tumor cells and presents viral antigens to cells of the immune system, hidden tumor antigens that the immune system can respond to will also be exposed. This would lead to clearance of the virus by the immune system and concurrent amplification of an antitumor immune response. Indeed, oncolytic viruses that eliminate xenografts in murine cancer models have been shown to induce an antitumor immune memory that prevents re-engraftment of the tumor cells. ${ }^{19-21}$

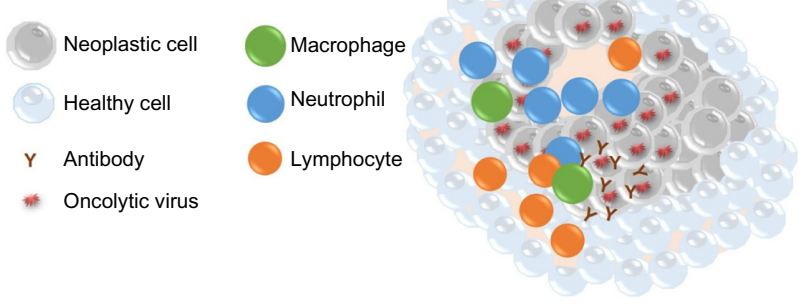

Figure 2 Mechanisms of oncolytic virus effects on neoplastic cells.

Notes: Oncolysis due to viral infection and immune stimulation are thought to occur simultaneously within the tumor microenvironment. Elimination of cancer cells occurs by direct infection of the tumor cell, virus replication, and subsequent cell lysis. An infiltrate of cytotoxic T lymphocytes and natural killer cells is often detected. These innate immune cells are able to lyse infected tumor cells through release of granzymes and perforins. Chemotaxis of neutrophils and macrophages to the site of virus infection is often seen and is likely due to the presence of cellular debris and chemokine release from infected and lysed cancer cells and/or healthy cells surrounding the tumor. Presentation of viral and tumor antigens by macrophages can lead to activation of helper T-cells and production of antiviral and antitumor antibodies by B lymphocytes. Ideally, this leads to elimination of the tumor.

\section{Oncolytic viruses as therapeutic vectors}

One of the most powerful attributes of oncolytic viral therapy is the ability to design viruses that express exogenous proteins. Viral expression of tumor-associated antigens, cytokines, or chemokines could promote antitumor immune responses that eliminate tumor cells. ${ }^{22,23}$ Intratumoral injection of an oncolytic poxvirus expressing granulocyte-monocyte colony-stimulating factor (GM-CSF) caused regression of the tumor and metastatic lesions. In this study, virus was not recovered from the metastatic lesions but T-cell infiltration was documented.${ }^{24}$ Furthermore, tumor angiogenesis can be limited and tumor growth suppressed by recombinant viruses expressing vascular endothelial growth factor (VEGF) inhibitors. ${ }^{25,26}$ Additionally, genetically altered oncolytic viruses can be used to target chemotherapeutics to the tumor and minimize the systemic effects of the drugs.

\section{Oncolytic virus treatment of canine cancers}

Many publications indicate that oncolytic viruses can replicate and lyse canine cancer cells in culture (Table 1) ${ }^{27-44}$ Murine xenograft models of canine cancers also have been successfully treated with oncolytic viruses (Table 2) ${ }^{29-35,38-43,45} \mathrm{~A}$ few publications have used replication-deficient adenoviruses as vectors for gene therapy in canine models (Table 3). ${ }^{46-50}$ Viruses that are replication deficient are actually using a gene therapy approach to cancer treatment, rather than functioning as true oncolytic viruses. These studies are included in this review because they demonstrate the effective use of viruses as therapeutic vectors in canine cancer patients. 

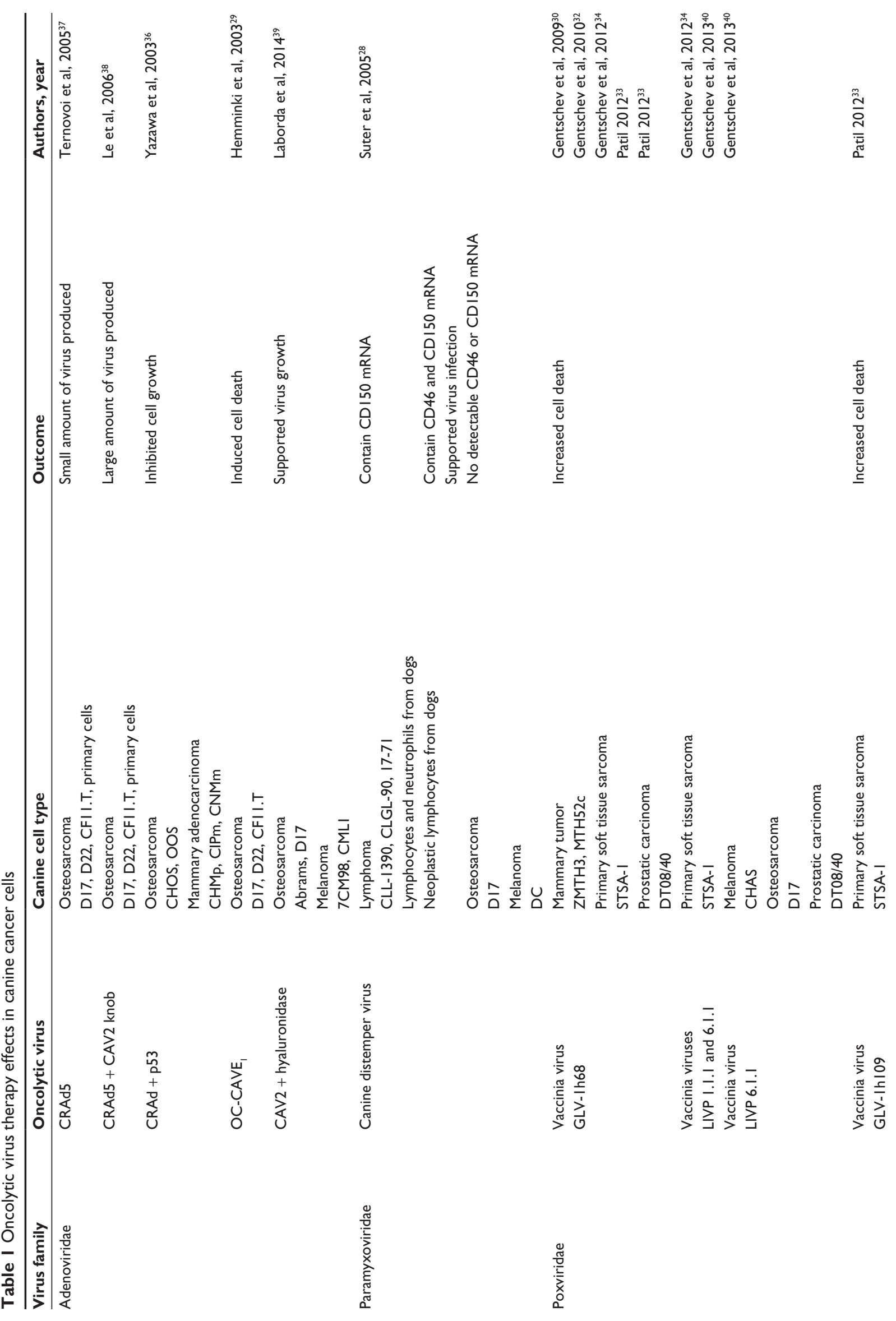


\begin{tabular}{|c|c|c|c|c|c|}
\hline 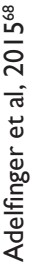 & 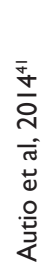 & 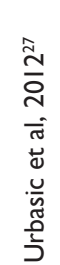 & 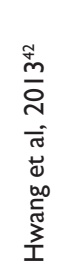 & 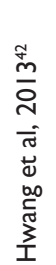 & 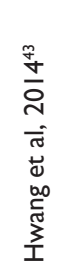 \\
\hline
\end{tabular}

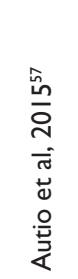
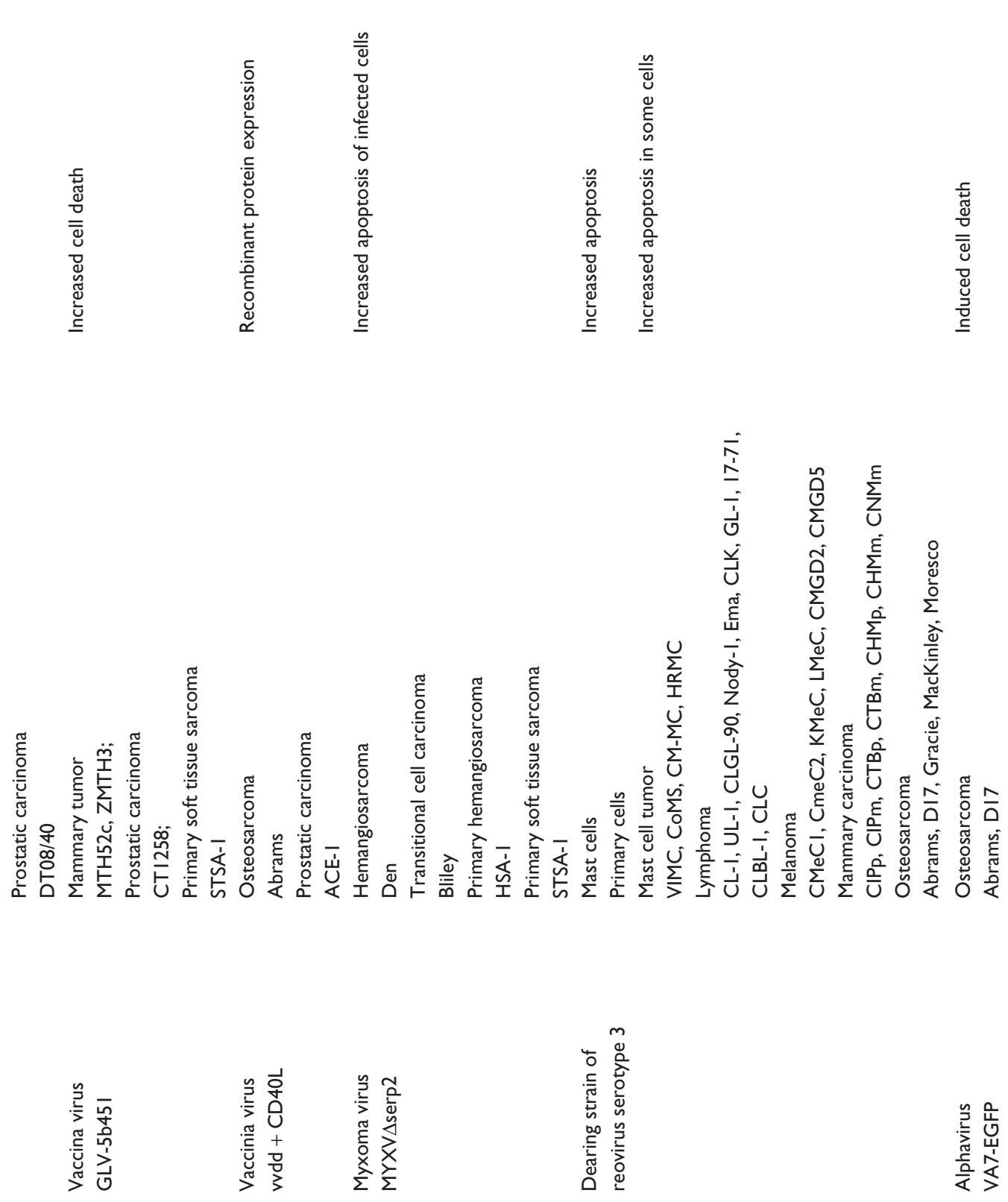

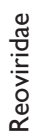

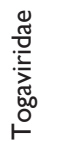


Table 2 Oncolytic virus treatment of murine xenograft models of canine cancer

\begin{tabular}{|c|c|c|c|c|}
\hline Virus family & Oncolytic virus & Canine cell type & Outcome & Authors, year \\
\hline \multirow[t]{10}{*}{ Adenoviridae } & CRAd5 + CAV2 & Osteosarcoma & Recombinant protein expression & Le et al, $2006^{38}$ \\
\hline & & D22 & & \\
\hline & CRAd + p53 & Osteosarcoma & Inhibited tumor growth & Kanaya et al, $201 \mathrm{I}^{45}$ \\
\hline & & POS, CHOS & & \\
\hline & OC-CAVE, & Osteosarcoma & Improved outcome & Hemminki $2003^{29}$ \\
\hline & & D22 & & \\
\hline & CAV2 + hyaluronidase & Osteosarcoma & Decreased tumor growth & Laborda et al, $2014^{39}$ \\
\hline & & Abrams & Slightly increased survival time & \\
\hline & & Melanoma & Mildly decreased tumor growth & \\
\hline & & CMLI & Slightly increased survival time & \\
\hline \multirow[t]{19}{*}{ Poxviridae } & Vaccinia virus & Mammary tumor & Decreased tumor burden & Gentschev et al, $2009^{30}$ \\
\hline & GLV-Ih68 & ZMTH3 & Mild weight loss & Gentschev et al, $2010^{32}$ \\
\hline & & & Virus in liver, lung, spleen, and ovary & \\
\hline & & Primary soft tissue sarcoma & Decreased tumor burden & Gentschev et al, 201 $2^{34}$ \\
\hline & & STSA-I & & \\
\hline & Vaccinia viruses & Primary soft tissue sarcoma & Decreased tumor burden & Gentschev et al, $2012^{34}$ \\
\hline & LIVP I.I.I and 6.I.I & STSA-I & Long-term survival & Gentschev et al, $2013^{40}$ \\
\hline & & & Virus in lung, liver, spleen, and kidney & \\
\hline & Vaccinia virus & Prostatic carcinoma & Decreased tumor burden & Gentschev et al, $2013^{40}$ \\
\hline & LIVP I.I.I & DT08/40 & & \\
\hline & Vaccinia virus & Primary soft tissue sarcoma & Decreased tumor burden & Patil $2012^{33}$ \\
\hline & GLV-IhI09 & STSA-I & Virus in liver, lung, kidney, and spleen & \\
\hline & & Prostatic carcinoma & Decreased tumor burden & \\
\hline & & DT08/40 & & \\
\hline & Vaccinia virus; & Primary soft tissue & Decreased tumor growth; Virus in & Adelfinger et al, $2015^{68}$ \\
\hline & GLV-5b45I & sarcoma; STSA-I & liver, lung, and spleen; Decreased tumor & \\
\hline & & & vascular density & \\
\hline & Vaccinia virus & Prostate carcinoma & Decreased tumor growth & Autio et al, $2014^{41}$ \\
\hline & vvdd & ACE-I & & \\
\hline \multirow[t]{4}{*}{ Reoviridae } & Dearing strain of & Mast cell tumor & Decreased tumor growth & Hwang et al, $2013^{42}$ \\
\hline & reovirus serotype 3 & VIMC, CoMS & Black tail syndrome & \\
\hline & & T-cell lymphoma & Decreased tumor growth & Hwang et al, $2014^{43}$ \\
\hline & & CL-I & & \\
\hline
\end{tabular}

More importantly for oncolytic virus research, studies have been published that report the safety profiles of replicating MYXV, modified adenovirus, and attenuated vesicular stomatitis and Semliki Forest viruses in healthy dogs (Table 4). ${ }^{35,51-57}$ Table 4 also summarizes the current studies using replicating oncolytic viruses in canine cancer patients. ${ }^{39}$ Clinical trials using oncolytic virotherapy in dogs are the next step toward advancing treatment options for dogs with cancer. Simultaneously, these studies may provide a more accurate predictive model of human response to virotherapy.

\section{Adenoviruses}

\section{Adenovirus background}

Adenoviruses are one of a few types of oncolytic viruses that have been evaluated in dogs. These viruses are non-enveloped,

Table 3 Adenovirus vectors tested in dogs with and without spontaneous tumors

\begin{tabular}{|c|c|c|c|c|}
\hline Virus vector & Dogs (n) & Route & Outcome (n) & Authors, year \\
\hline Recombinant Ad6 (two constructs) & Healthy (3-6) & Intramuscular & No detrimental effects & Peruzzi et al, $2010^{46}$ \\
\hline Ad6-dTERT & Lymphoma (I4) & Intramuscular & Prolonged survival time & Peruzzi et al, $2010^{47}$ \\
\hline Ad-IFN $\gamma$ & Astrocytoma (I) & Intratumoral & Prolonged survival time & Pluhar et al, $2010^{48}$ \\
\hline \multirow[t]{6}{*}{ AdCD40L } & Oral melanoma (I) & Intratumoral & Complete remission (2) & von Euler et al, $2008^{49}$ \\
\hline & Dermal melanoma (I) & & & \\
\hline & Melanoma (19) & Intratumoral & Complete remission (5) & Westberg et al, $2013^{50}$ \\
\hline & & & Partial remission (8) & \\
\hline & & & Stable disease (4) & \\
\hline & & & Progressive disease (2) & \\
\hline
\end{tabular}


Table 4 Oncolytic viruses tested in dogs with and without spontaneous tumors

\begin{tabular}{|c|c|c|c|c|c|}
\hline Virus family & Virus & Dogs & Route & Outcome & Authors, year \\
\hline \multirow[t]{5}{*}{ Adenoviridae } & $\begin{array}{l}\text { Recombinant Ad5 } \\
\text { intended for use in humans }\end{array}$ & Healthy (6) & Prostatic (3) & $\begin{array}{l}\text { Transgene expression in } \\
\text { prostate }\end{array}$ & Barton et al, $2006^{35}$ \\
\hline & & & Pancreatic (3) & $\begin{array}{l}\text { Neutrophilia, pancreatitis, } \\
\text { hepatitis }\end{array}$ & Freytag et al, $2007^{55}$ \\
\hline & $\begin{array}{l}\text { CRAd with prostate- } \\
\text { specific promoter intended } \\
\text { for use in humans }\end{array}$ & Healthy (4) & Prostatic & $\begin{array}{l}\text { Virus in prostate, vas deferens, } \\
\text { iliac lymph nodes, bladder, } \\
\text { heart, and liver } \\
\text { Transgene expression in } \\
\text { prostate only }\end{array}$ & Lu et al, $2013^{56}$ \\
\hline & OC-CAVE & $\begin{array}{l}\text { Healthy (3) } \\
\text { Immunosuppressed (3) }\end{array}$ & Intravenous & $\begin{array}{l}\text { Neutropenia } \\
\text { Virus in feces, urine, liver, and } \\
\text { spleen }\end{array}$ & Smith et al, $2006^{52}$ \\
\hline & CAV2 + hyaluronidase & $\begin{array}{l}\text { Osteosarcoma (2) } \\
\text { Metastatic carcinoma (I) } \\
\text { Mast cell tumor (I) } \\
\text { Fibrosarcoma (I) } \\
\text { Adenoma (I) }\end{array}$ & Intratumoral & $\begin{array}{l}\text { Surgical removal }(I) \\
\text { Partial remission (I) } \\
\text { Progressive disease (4) }\end{array}$ & Laborda et al, $2014^{39}$ \\
\hline \multirow[t]{4}{*}{ Poxviridae } & $\begin{array}{l}\text { Vaccinia virus } \\
\text { LIVP 6.I.I }\end{array}$ & Solid subcutaneous tumors & Unknown & $\begin{array}{l}\text { Completed trial } \\
\text { No detrimental effects }\end{array}$ & $\begin{array}{l}\text { Szalay, } 2014, \\
\text { Unpublished data }\end{array}$ \\
\hline & $\begin{array}{l}\text { Vaccinia virus } \\
\text { vvdd + CD40L }\end{array}$ & $\begin{array}{l}\text { Healthy ( } 2 \text { ) } \\
\text { Incurable solid tumors }\end{array}$ & Unknown & Ongoing trial & $\begin{array}{l}\text { Hemminki, } 2015 \\
\text { Unpublished data }\end{array}$ \\
\hline & $\begin{array}{l}\text { Myxoma virus } \\
\text { Varied strains }\end{array}$ & Healthy & $\begin{array}{l}\text { Subcutaneous } \\
\text { Intramuscular }\end{array}$ & No detrimental effects & $\begin{array}{l}\text { Górski et al, 1994' } \\
\text { Bull and Dickinson } \\
1937^{54}\end{array}$ \\
\hline & $\begin{array}{l}\text { Myxoma virus } \\
\text { MYXV } \Delta \operatorname{serp} 2\end{array}$ & $\begin{array}{l}\text { Mast cell tumor }(I) \\
\text { Soft tissue sarcoma }(10)\end{array}$ & Intratumoral & $\begin{array}{l}\text { Surgical removal }(\mathrm{I}) \\
\text { Ongoing trial }\end{array}$ & $\begin{array}{l}\text { MacNeill, 20I5, } \\
\text { Unpublished data }\end{array}$ \\
\hline Rhabdoviridae & $\begin{array}{l}\text { Vesicular stomatitis virus } \\
\text { VSV-IFN } \beta \text {-NIS }\end{array}$ & Healthy (5) & Intravenous & $\begin{array}{l}\text { Maximum tolerated dose }=10^{10} \\
\mathrm{TCID}_{50}\end{array}$ & LeBlanc et al, $2013^{53}$ \\
\hline Togaviridae & $\begin{array}{l}\text { Alphavirus } \\
\text { VA7-EGFP }\end{array}$ & $\begin{array}{l}\text { Healthy (2) } \\
\text { Intravenous }\end{array}$ & Intravenous & No detrimental effects & Autio et al, $2015^{89}$ \\
\hline
\end{tabular}

Note: $\operatorname{TCID} 50$ = tissue culture infectious dose that produces cytopathic effects in $50 \%$ of the cells.

linear, double-stranded DNA viruses. Most adenoviruses cause mild upper respiratory tract infections, including canine adenovirus (CAV) 2. Other adenoviruses cause severe disease. For example, CAV1 is the cause of infectious canine hepatitis. Attenuated forms of CAV2 have safely been used for many years as vaccines to protect dogs against CAV1. This has helped establish the use of CAV2 as an oncolytic virus in dogs.

Adenoviruses are classified into serotypes that have varied cell tropism. The cell tropism of adenoviruses can be modified to direct infection to cell types lacking the natural viral receptors through transductional targeting or genetic modification. Adenoviruses are promising as vectors for expression of exogenous antigens; however, their ability to maintain gene expression in cells is linked to their ability to evade the immune system and prevent cell death during viral replication, attributes which may make them less ideal as oncolytic virus therapies. ${ }^{22}$ Nonetheless, adenoviruses have been shown to be effective oncolytic viruses in many cancer models.

\section{Adenovirus effects on canine cancer cell cultures and xenografts}

Many adenovirus constructs designed to be used in clinical trials to treat dogs with cancer were first tested in canine cell cultures and murine xenograft models of canine cancer. Conditionally replicating human adenovirus (CRAd) 5 was shown to replicate in several canine cancer cell lines and primary canine cancer cell cultures, but the level of virus production is moderate in canine cells as compared to human cells. ${ }^{37}$ When functional components encoded by CAV2 were inserted genetically into CRAd5, virus replication in canine osteosarcoma cells was improved and increased expression of a reporter gene encoded by the virus was observed in a murine xenograft model of canine osteosarcoma. ${ }^{38}$ Similarly, a CRAd that expresses canine p53 inhibited the growth of canine cancer cells and tumors in two murine xenograft models of canine osteosarcoma. ${ }^{36,45}$ A conditionally replicating CAV2 (OC-CAVE $)_{1}$ ) was constructed with an osteocalcin promoter to drive E1a gene expression and limit viral replication to osteoblasts. This virus elicited cell death 
in canine osteosarcoma cultures and improved outcome in a murine xenograft model of canine osteosarcoma. ${ }^{29}$ When osteosarcoma cells were used as carriers to deliver this virus intravenously, viral expression in the liver was minimized and tumor growth in murine models of canine osteosarcoma was inhibited. ${ }^{31}$

\section{Adenovirus safety profiles in healthy dogs}

The safety profiles of several recombinant adenoviruses were tested in healthy dogs before being used in cancer patients. As preliminary information for human clinical trials, a replication-competent recombinant Ad5 was injected into the prostate or pancreas of dogs (three dogs per group). Very few data were collected following prostatic injection except to verify that transgene expression was observed in the prostate. ${ }^{35}$ Dogs with pancreatic injections developed neutrophilia, acute pancreatitis, and hepatitis. ${ }^{55}$ The safety of an adenovirus designed to express beta-galactosidase driven by a prostate-specific promoter can be implied from a recent study which injected $4.8 \times 10^{9}$ plaque-forming units (pfu) of virus into the prostate glands of healthy dogs. Viral DNA could be detected in several tissues 72 hours after injection, but transgene expression by the modified viruses was only observed in the prostate. ${ }^{56}$ As preliminary data for canine

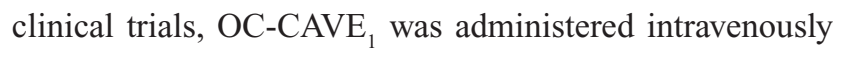
to six dogs; neutropenia was observed and virus was recovered from feces, urine, liver, and spleen at 96 hours after virus inoculation. ${ }^{52}$ More recently, replication-deficient Ad6 recombinant viruses were administered intramuscularly to groups of three to six dogs with no adverse effects. ${ }^{46}$

\section{Adenovirus clinical outcomes in cancer-bearing dogs}

Clinical trials using adenoviruses to treat dogs with cancer have shown promising results with few side effects. Both replication-deficient adenoviruses and oncolytic adenoviruses have been studied in cancer-bearing dogs.

\section{Adenovirus vectors}

A replication-deficient Ad5 expressing CD40 ligand (AdCD40L) was designed to target the virus to cells expressing $\alpha_{v} \beta_{3}$ integrin as a means of inhibiting tumor angiogenesis. This virus was injected intratumorally into a dog with stage III oral melanoma and a dog with a melanoma on his eyelid; tumor resolution was observed in both patients. ${ }^{49}$ Additionally, promising results were reported in 19 cases of canine melanoma treated with intratumoral AdCD40L followed by either surgery or immunotherapy. Lymphocyte infiltration into the tumors was detected in eight of eleven dogs. Five of the 19 patients were reported to have complete disease remission, eight showed partial remission, four had stabile disease, and only two experienced progressive disease. ${ }^{50}$

One of the recombinant replication-deficient Ad6 viruses (Ad6-dTERT) tested in healthy dogs was used as an adjunct to chemotherapy and DNA vaccination in a clinical trial to treat dogs with high-grade B-cell lymphomas. Vaccinated dogs treated with the virus had significantly prolonged survival time compared to dogs treated with chemotherapy alone. ${ }^{47}$ Excellent results also were observed in a dog with astrocytoma following debulking surgery, intratumoral injection of an adenovirus expressing interferon- $\gamma(\mathrm{Ad}-\mathrm{IFN} \gamma)$, and vaccination with a tumor homogenate. ${ }^{48}$

\section{Oncolytic adenovirus}

A recombinant CAV2 virus with disruption of E1a, modification of cell receptor tropism, and hyaluronidase expression was evaluated in canine osteosarcoma and melanoma cell lines, murine xenograft models of canine osteosarcoma and melanoma, and in cancer-bearing dogs. ${ }^{39}$ Cell cultures that expressed the coxsackievirus and adenovirus receptor and expressed hyperphosphorylated retinoblastoma protein supported virus growth. When given $10^{11}$ viral particles intravenously, healthy Balb/c mice experienced weight loss, severe thrombocytopenia, moderate lymphopenia, and mild increases in liver enzymes. Virus DNA could be isolated from most tissues. However, in nude mice bearing canine osteosarcoma and melanoma xenografts, a mild decrease in tumor growth and slight increase in survival time were observed following three intratumoral injections of $10^{10}$ viral particles. No weight loss was detected in these mice. The treatment response to this virus varied in six dogs with cancer. Dogs were given at least one intratumoral injection of $10^{12}$ viral particles. Tumor types that were treated included two cases of humoral osteosarcoma, a metastatic carcinoma involving the liver, a cutaneous mast cell tumor, a subcutaneous fibrosarcoma, and a sweat gland adenoma of the prepuce. Of these six cases, four dogs (with osteosarcomas, mast cell tumor, and fibrosarcoma) experienced swelling or bleeding at the site of virus injection. No treatment response was observed in patients with osteosarcoma or metastatic carcinoma. The dog with a mast cell tumor developed disseminated intravascular coagulopathy. However, positive outcomes were seen in the patient with fibrosarcoma (tumor removal following virus therapy) and the patient with a sweat gland adenoma (partial remission for 6 months). ${ }^{39}$ 


\section{Paramyxoviruses}

Paramyxoviruses, including measles virus and canine distemper virus, have been tested in canine cancer cells. Paramyxoviruses are negative-stranded RNA viruses that induce syncytia formation in the cells they infect. These viruses infect and deplete lymphocytes. If constructed correctly, they may be effective treatments for lymphoma. Suter et al demonstrated that canine lymphoid cell lines and lymphocytes and polymorphonuclear cells isolated from healthy dogs contain mRNA which encodes the CD150 receptor needed for measles virus and canine distemper virus entry. Neoplastic canine lymphocytes isolated from dogs with lymphoma also contain mRNA for a second virus receptor, CD46. Importantly, canine distemper virus could infect some canine lymphoid cell lines and neoplastic lymphoid cells. No detectable mRNA for either receptor was found in canine osteosarcoma or melanoma cells. ${ }^{28}$

\section{Poxviruses}

\section{Poxvirus background}

Poxviruses have many attributes that make them excellent oncolytic viruses. Unlike many oncolytic viruses, poxviruses do not require a specific cellular receptor to infect cells. ${ }^{58}$ However, due to their large size, they naturally target neoplasms where new leaky vessels are being formed. ${ }^{22}$ Poxviruses are enveloped, double-stranded DNA viruses with genomes that replicate with high fidelity and allow for insertion of up to $25 \mathrm{~kb}$ of contiguous DNA, making them excellent vectors for exogenous protein expression. ${ }^{59}$ Poxviruses have their own replication machinery and remain in the cytoplasm of infected cells, so recombination of viral DNA into the host DNA does not occur and gene transcription begins immediately upon entering the host cell. Additionally, poxvirus virions are released from infected cells before the cells are lysed, allowing for efficient spread of virus to neighboring cancer cells..$^{22}$ Importantly, poxviruses elicit a strong cell-mediated immune response and are ultimately cleared from the body by the humoral immune system, preventing poxviruses from causing latent or recurrent infection. ${ }^{60-63}$

\section{VACV}

VACV is the poxvirus most frequently used in oncolytic virotherapy and was the vaccine used to eradicate smallpox. Wild-type VACV causes mild-to-moderate disease in several species including humans and mice. Genetic manipulation of VACV has produced attenuated viruses with improved targeting of malignant cells and antitumor effects. ${ }^{15,64-67}$ Recombinant VACVs have shown promising results in many murine xenografts of human tumors and in some human clinical trials.

Several VACV constructs have been evaluated in canine cancer cell cultures and murine xenografts with canine tumors. Vaccinia viral recombinants with deletion of three viral genes have been shown to replicate in canine tumor cells and significantly decrease tumor volume in murine xenograft models of canine mammary tumors and soft tissue sarcoma. ${ }^{30,32,34}$ However, the virus caused mild weight loss and replicated at low levels in the liver, lung, spleen, and ovary of mice..$^{32} \mathrm{~A}$ similar recombinant VACV encoding antiVEGF was effective in reducing tumor volume in mice with canine soft tissue sarcoma or prostate carcinoma xenografts. Weight loss was not evident in these mice, but low levels of viral replication were detected in the liver, lung, kidney, and spleen of the mice with soft tissue sarcoma xenografts. ${ }^{33}$ Yet another modified VACV (LIVP 6.1.1) induced cell death in canine soft tissue sarcoma, melanoma, osteosarcoma, and prostate carcinoma cells. This virus effectively reduced tumor growth of canine soft tissue sarcoma and prostate carcinoma xenografts in mice. ${ }^{40}$ Similarly, when LIVP 6.1.1 was modified to express an anti-VEGF antibody, the new virus (GLV-5b451) induced cell death in cainine soft tissue sarcoma, mammary tumor, and prostate carcinoma cells and reduced tumor growth of canine soft tissue sarcoma xenografts in mice. ${ }^{68}$

Variations of a recombinant VACV with deletion of genes encoding thymidine kinase and vaccinia growth factor (vvdd) have shown positive results in many murine xenograft models of human cancer. ${ }^{15,69,70}$ Recently, treatment with two intratumoral injections of $10^{5} \mathrm{pfu}$ of vvdd expressing luciferase (vvdd-luc) was effective at decreasing growth of a canine prostate tumor in nude mice. ${ }^{41}$ Another recombinant vvdd encoding human $\mathrm{CD} 40 \mathrm{~L}$ and the tdTomato reporter protein (vvdd-hCD40L-tdTomato) was shown to express recombinant proteins in canine osteosarcoma and prostate carcinoma cell lines. Incubation of $5 \times 10^{6} \mathrm{pfu}$ of this virus with canine tumor biopsy sections resulted in viral transduction of cells in six of nine samples. ${ }^{41}$

Clinical trials using vvdd-hCD40L-tdTomato have been started at the University of Helsinki Faculty of Veterinary Medicine (Helsinki, Finland). ${ }^{41}$ Additionally, an unpublished clinical trial using a modified VACV to treat dogs with cancer was recently completed at Angel Care Cancer Center (Carlsbad, CA, USA). Results of that study are currently being analyzed; importantly, no adverse effects of virus inoculation were observed (AA Szalay, University of Würzburg, Germany, personal communication, August 2015). 


\section{MYXV}

MYXV is a poxvirus that shares most of the attributes of VACV, but does not cause disease in any animal except the rabbit. ${ }^{51,71-77}$ MYXV infects tumor cells from several species, including dogs and cats. ${ }^{27,78-81}$ In rodent cancer models, MYXV treatment has eliminated some glioma xenografts, and reduced tumor burden in several types of xenografts and allografts. $^{82-89}$

A pilot study to assess the safety of MYXV deleted for serp2 (MYXVAserp2) in dogs with soft tissue sarcomas is currently underway at the Colorado State University College of Veterinary Medicine and Biomedical Sciences (Fort Collins, CO, USA).

Prior to the study at Colorado State University, one canine cancer patient has been treated with MYXV $\Delta$ serp2.
The patient was a 13-year-old, female, spayed Labrador retriever with a subcutaneous mast cell tumor (grade II) that was treated by intratumoral inoculation with $5 \times 10^{7} \mathrm{pfu}$ of MYXV $\Delta$ serp2. The poxvirus treatment was given once following biopsy of the mass and was repeated 5 days later. Eight days after the second treatment, the tumor was surgically resected. The biopsy taken prior to treatment contained large numbers of neoplastic mast cells (which appear deep purple with Giemsa staining). The tumor removed following treatment showed some necrosis and contained fewer mast cells and increased numbers of plasma cells as compared to the untreated biopsy sample (Figure 3). There were no clinical signs of disease following virus treatment and, 20 months postoperatively, the tumor has not recurred (MacNeill, unpublished data 2015).
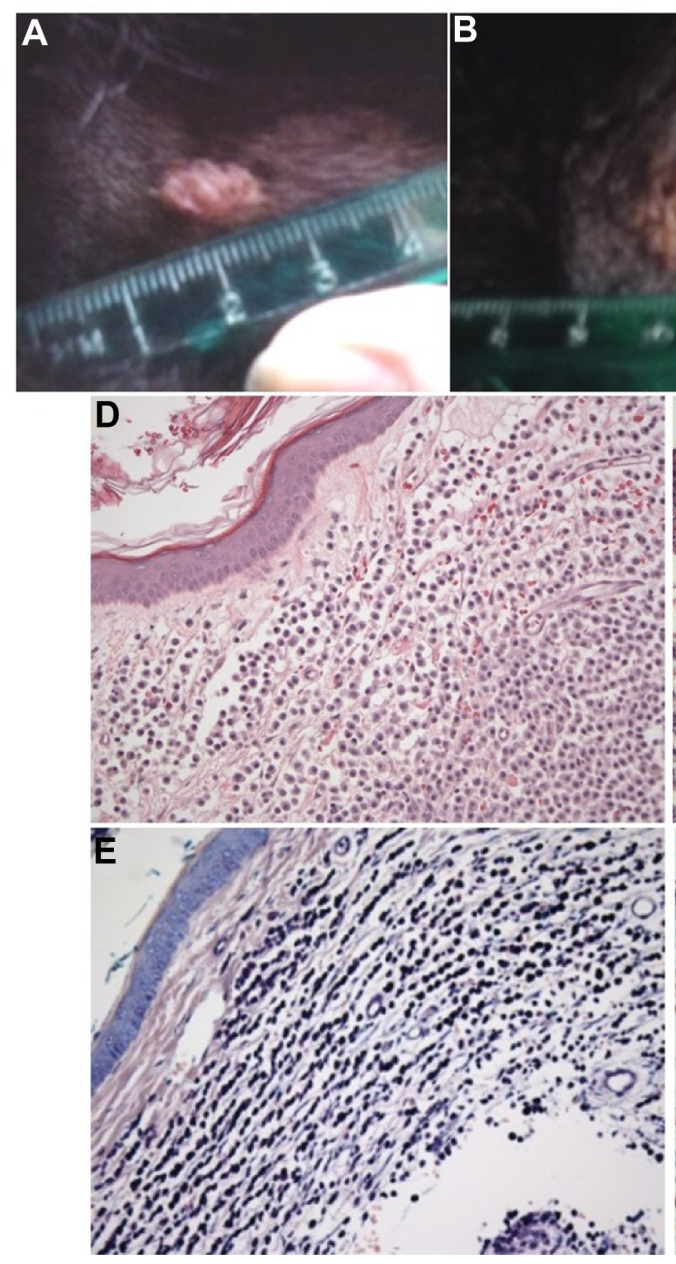
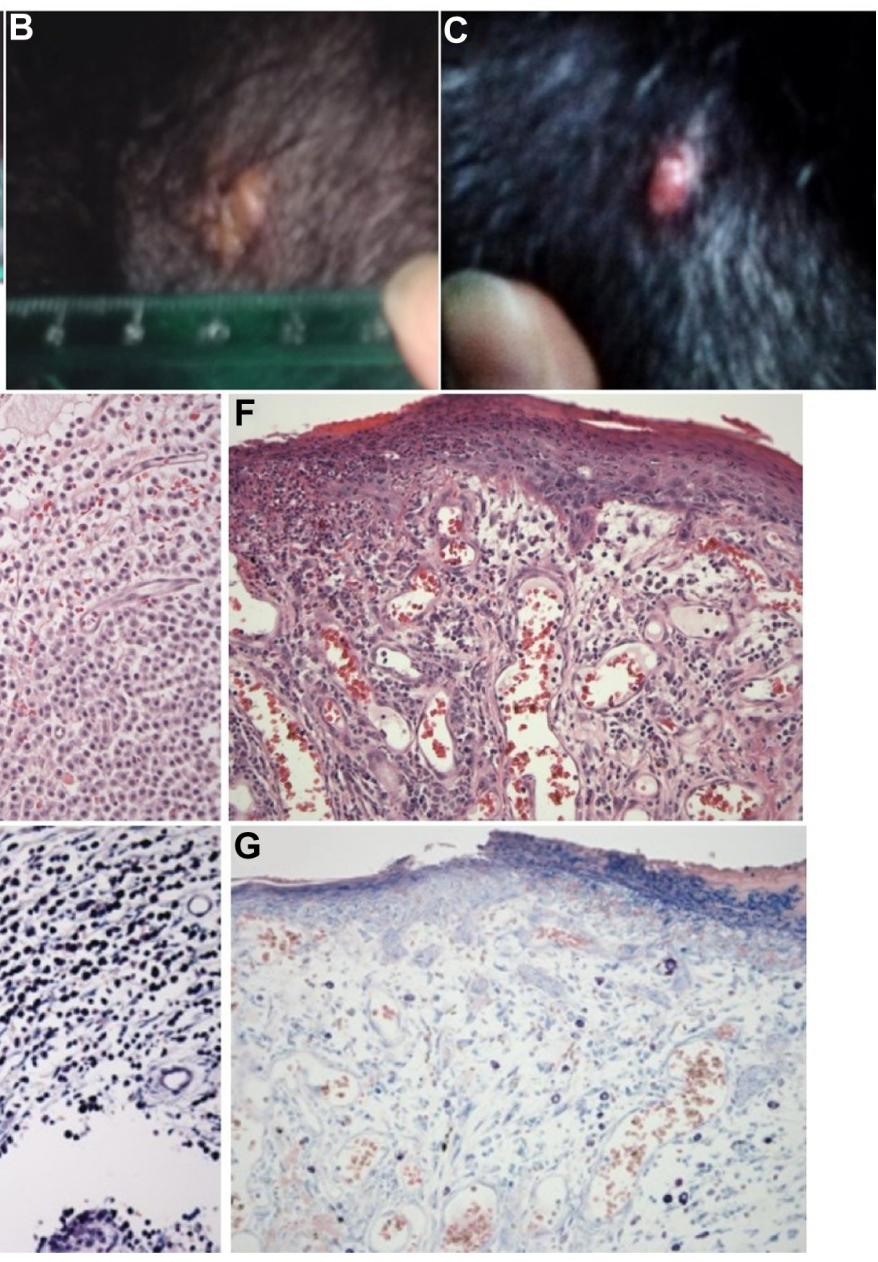

Figure 3 Images of a cutaneous mast cell tumor in a dog treated with an oncolytic virus. (A, B \& C) Photographs of the gross lesion taken immediately prior to (A) the first recombinant myxoma virus (MYXV $\Delta$ serp2) injection, (B) the second MYXV $\Delta$ serp2 treatment, and (C) surgery. (D \& E) Photomicrographs of a histologic section from the mast cell tumor prior to MYXV $\Delta$ serp2 treatment [(D) hematoxylin and eosin (H \& E) stain, 200× magnification; (E) Giemsa stain, 200× magnification]. (F \& G) Photomicrographs of a histologic section from the mast cell tumor following two injections of MYXV $\Delta$ serp2 [(F) H \& E stain, 200× magnification; (G) Giemsa stain, 200x magnification]. sa stain, 200× magnification].

Notes: (D \& E) A dermal mass was observed that was composed of round cells that stain deep purple with Giemsa stain, consistent with a mast cell tumor. (F and $\mathbf{G )}$ The surgically removed mass had fewer mast cells and more plasma cells than the untreated tumor. 


\section{Reovirus}

Reoviruses are small, double-stranded RNA viruses that are ubiquitous and typically cause subclinical infections. Recently, the Mizuno laboratory (Yamaguchi, Japan) published three papers showing the potential of this virus for treatment of canine cancers. ${ }^{42-44}$ Hwang et al found that canine mast cells and mast cell tumors are susceptible to apoptosis 72 hours following inoculation with 70 pfu of the Dearing strain of reovirus (serotype 3 ) per cell. ${ }^{42}$ In nonobese diabetic/severe combined immunodeficiency (NOD/SCID) mice with mast cell tumor xenografts, significant decreases in tumor growth were observed after intratumoral injection of $7 \times 10^{7} \mathrm{pfu}$; however, black tail syndrome occurred in a subset of the mice. ${ }^{42}$ Similarly, reovirus can induce apoptosis in a subset of canine lymphoma cell lines 72 hours postinoculation with 70 pfu per cell and can reduce tumor growth in a NOD/SCID xenograft model of canine T-cell lymphoma (CL-1 cells) following treatment with $10^{8}$ pfu. ${ }^{43}$ Igase et al also investigated the susceptibility of solid canine tumor cell lines to reovirus. ${ }^{44}$ They reported that apoptosis occurs 72 hours following inoculation with 70 pfu of reovirus per cell in a subset of melanoma and mammary carcinoma cell lines. Osteosarcoma cell lines were less susceptible to reovirus infection. ${ }^{44}$

\section{Togaviridae}

Very recently, an attenuated Semliki Forest virus (VA7-EGFP) was shown to induce cell death in two canine osteocarcoma cell lines. ${ }^{57}$ Semliki Forest virus is a positive single stranded RNA virus classified in the Alphavirus genus of the Togavirus family. Although a virulent Semliki Forest virus strain caused neurologic disease in young dogs when administered by intraperitoneal or intrecerebral injection, the attenuated form used in this study was safe in Beagles when given intravenously at $2 \times 10^{5}$ pfu..$^{57,90}$

\section{Conclusion}

Oncolytic viruses are exciting novel therapeutic options that could benefit dogs with cancer while providing better insight into which recombinant viruses will be most effective in human cancer patients. Conversely, as more oncolytic viruses enter human clinical trials, more oncolytic therapeutics may become available for use in companion animals. Prudent use of new oncolytic viruses will require an understanding of the biology of the viruses and the exogenous proteins they express. There is promise that oncolytic viruses will soon be a new, powerful treatment option for veterinary patients with cancer.

\section{Disclosure}

The author reports no conflicts of interest in this work.

\section{References}

1. Pol J, Bloy N, Obrist F, et al. Trial Watch: Oncolytic viruses for cancer therapy. Oncoimmunology. 2014;3:e28694.

2. Kirn DH. The end of the beginning: oncolytic virotherapy achieves clinical proof-of-concept. Mol Ther. 2006;13(2):237-238.

3. Breitbach CJ, Bell JC, Hwang TH, Burke J. The emerging therapeutic potential of the oncolytic immunotherapeutic Pexa-Vec (JX-594). Oncolytic Virother. 2015;4:25-31.

4. Sampath P, Thorne SH. Novel therapeutic strategies in human malignancy: combining immunotherapy and oncolytic virotherapy. Oncolytic Virother. 2015;4:75-82.

5. Dock G. The influence of complicating diseases upon leukaemia Am J Med Sci. 1904;127:563-592.

6. Huebner RJ, Rowe WP, Schatten WE, Smith RR, Thomas LB. Studies on the use of viruses in the treatment of carcinoma of the cervix. Cancer. 1956;9(6):1211-1218.

7. Yu W, Fang H. Clinical trials with oncolytic adenovirus in China. Curr Cancer Drug Targets. 2007;7(2):141-148.

8. Patil SS, Gentschev I, Nolte I, Ogilvie G, Szalay AA. Oncolytic virotherapy in veterinary medicine: current status and future prospects for canine patients. J Transl Med. 2012;10:3.

9. Gentschev I, Patil SS, Petrov I, Cappello J, Adelfinger M, Szalay AA. Oncolytic virotherapy of canine and feline cancer. Viruses. 2014; 6(5):2122-2137.

10. Bell J. Oncolytic viruses: immune or cytolytic therapy? Mol Ther. 2014;22(7):1231-1232.

11. Porrello A, Cardelli P, Spugnini EP. Oncology of companion animals as a model for humans. an overview of tumor histotypes. J Exp Clin Cancer Res. 2006;25(1):97-105.

12. Davis BW, Ostrander EA. Domestic dogs and cancer research: a breedbased genomics approach. ILAR J. 2014;55(1):59-68.

13. Thorne $\mathrm{SH}$. Immunotherapeutic potential of oncolytic vaccinia virus. Front Oncol. 2014;4:155.

14. Barker DD, Berk AJ. Adenovirus proteins from both E1B reading frames are required for transformation of rodent cells by viral infection and DNA transfection. Virology. 1987;156(1):107-121.

15. McCart JA, Ward JM, Lee J, et al. Systemic cancer therapy with a tumor-selective vaccinia virus mutant lacking thymidine kinase and vaccinia growth factor genes. Cancer Res. 2001;61(24): 8751-8757.

16. Puhlmann M, Gnant M, Brown CK, Alexander HR, Bartlett DL. Thymidine kinase-deleted vaccinia virus expressing purine nucleoside phosphorylase as a vector for tumor-directed gene therapy. Hum Gene Ther. 1999;10:649-657.

17. Tsung K, Meko JB, Peplinski GR, Tsung YL, Norton JA. IL-12 induces T helper 1-directed antitumor response. J Immunol. 1997; 158(7):3359-3365.

18. Zou W. Immunosuppressive networks in the tumour environment and their therapeutic relevance. Nat Rev Cancer. 2005;5(4):263-274.

19. Kirn DH, Wang Y, Le Boeuf F, Bell J, Thorne SH. Targeting of interferonbeta to produce a specific, multi-mechanistic oncolytic vaccinia virus. PLoS Med. 2007;4(12):e353.

20. Koks CA, Garg AD, Ehrhardt M, et al. Newcastle disease virotherapy induces long-term survival and tumor-specific immune memory in orthotopic glioma through the induction of immunogenic cell death. Int J Cancer. 2015;136(5):E313-E325.

21. Gibson H, Munns S, Freytag S, et al. Immunotherapeutic intervention with oncolytic adenovirus in mouse mammary tumors. Oncoimmunology. 2015;4(1):e984523.

22. Thorne SH, Bartlett DL, Kirn DH. The use of oncolytic vaccinia viruses in the treatment of cancer: a new role for an old ally? Curr Gene Ther. $2005 ; 5: 429-443$. 
23. Vacchelli E, Aranda F, Obrist F, et al. Trial watch: Immunostimulatory cytokines in cancer therapy. Oncoimmunology. 2014;3:e29030.

24. Mastrangelo MJ, Maguire HC Jr, Eisenlohr LC, et al. Intratumoral recombinant GM-CSF-encoding virus as gene therapy in patients with cutaneous melanoma. Cancer Gene Ther. 1999;6:409-422.

25. Kottke T, Hall G, Pulido J, et al. Antiangiogenic cancer therapy combined with oncolytic virotherapy leads to regression of established tumors in mice. J Clin Invest. 2010;120(5):1551-1560.

26. Guse K, Sloniecka M, Diaconu I, et al. Antiangiogenic arming of an oncolytic vaccinia virus enhances antitumor efficacy in renal cell cancer models. J Virol. 2010;84(2):856-866.

27. Urbasic AS, Hynes S, Somrak A, et al. Oncolysis of canine tumor cells by myxoma virus lacking the serp2 gene. Am J Vet Res. 2012; 73(8):1252-1261.

28. Suter SE, Chein MB, von Messling V, et al. In vitro canine distemper virus infection of canine lymphoid cells: a prelude to oncolytic therapy for lymphoma. Clin Cancer Res. 2005;11(4):1579-1587.

29. Hemminki A, Kanerva A, Kremer EJ, et al. A canine conditionally replicating adenovirus for evaluating oncolytic virotherapy in a syngeneic animal model. Mol Ther. 2003;7(2):163-173.

30. Gentschev I, Stritzker J, Hofmann E, et al. Use of an oncolytic vaccinia virus for the treatment of canine breast cancer in nude mice: preclinical development of a therapeutic agent. Cancer Gene Ther. 2009;16(4):320-328.

31. Alcayaga-Miranda F, Cascallo M, Rojas JJ, Pastor J, Alemany R. Osteosarcoma cells as carriers to allow antitumor activity of canine oncolytic adenovirus in the presence of neutralizing antibodies. Cancer Gene Ther. 2010;17(11):792-802.

32. Gentschev I, Ehrig K, Donat U, et al. Significant growth inhibition of canine mammary carcinoma xenografts following treatment with oncolytic vaccinia virus GLV-1h68. J Oncol. 2010; 2010:736907

33. Patil SS, Gentschev I, Adelfinger M, et al. Virotherapy of canine tumors with oncolytic vaccinia virus GLV-1h109 expressing an anti-VEGF single-chain antibody. PLoS One. 2012;7(10):e47472.

34. Gentschev I, Adelfinger M, Josupeit R, et al. Preclinical evaluation of oncolytic vaccinia virus for therapy of canine soft tissue sarcoma. PLoS One. 2012; 7(5):e37239.

35. Barton KN, Paielli D, Zhang Y, et al. Second-generation replicationcompetent oncolytic adenovirus armed with improved suicide genes and ADP gene demonstrates greater efficacy without increased toxicity. Mol Ther. 2006;13(2):347-356.

36. Yazawa M, Setoguchi A, Hong SH, et al. Effect of an adenoviral vector that expresses the canine p53 gene on cell growth of canine osteosarcoma and mammary adenocarcinoma cell lines. Am J Vet Res. 2003; 64(7):880-888.

37. Ternovoi VV, Le LP, Belousova N, Smith BF, Siegal GP, Curiel DT. Productive replication of human adenovirus type 5 in canine cells. J Virol. 2005;79(2):1308-1311.

38. Le LP, Rivera AA, Glasgow JN, et al. Infectivity enhancement for adenoviral transduction of canine osteosarcoma cells. Gene Ther. 2006; 13(5):389-399.

39. Laborda E, Puig-Saus C, Rodriguez-García A, et al. A pRb-responsive, RGD-modified, and hyaluronidase-armed canine oncolytic adenovirus for application in veterinary oncology. Mol Ther. 2014; 22(5):986-998.

40. Gentschev I, Patil SS, Adelfinger M, et al. Characterization and evaluation of a new oncolytic vaccinia virus strain LIVP6.1.1 for canine cancer therapy. Bioengineered. 2013;4(2):84-89.

41. Autio K, Knuuttila A, Kipar A, et al. Anti-tumour activity of oncolytic Western Reserve vaccinia viruses in canine tumour cell lines, xenografts, and fresh tumour biopsies. Vet Comp Oncol. Epub 2014 Oct 10.

42. Hwang CC, Umeki S, Kubo M, et al. Oncolytic reovirus in canine mast cell tumor. PLoS One. 2013;8(9):e73555.

43. Hwang CC, Umeki S, Igase M, et al. The effects of oncolytic reovirus in canine lymphoma cell lines. Vet Comp Oncol. Epub 2014 Oct 15 .
44. Igase M, Hwang CC, Coffey M, Okuda M, Noguchi S, Mizuno T. The oncolytic effects of reovirus in canine solid tumor cell lines. J Vet Med Sci. 2015;77(5):541-548.

45. Kanaya N, Yazawa M, Goto-Koshino Y, et al. Anti-tumor effect of adenoviral vector-mediated $\mathrm{p} 53$ gene transfer on the growth of canine osteosarcoma xenografts in nude mice. J Vet Med Sci. 2011;73(7): 877-883.

46. Peruzzi D, Mesiti G, Ciliberto G, La Monica N, Aurisicchio L. Telomerase and HER-2/neu as targets of genetic cancer vaccines in dogs. Vaccine. 2010;28(5):1201-1208.

47. Peruzzi D, Gavazza A, Mesiti G, et al. A vaccine targeting telomerase enhances survival of dogs affected by B-cell lymphoma. Mol Ther. 2010;18(8):1559-1567.

48. Pluhar GE, Grogan PT, Seiler C, et al. Anti-tumor immune response correlates with neurological symptoms in a dog with spontaneous astrocytoma treated by gene and vaccine therapy. Vaccine. 2010;28(19):3371-3378.

49. von Euler H, Sadeghi A, Carlsson B, et al. Efficient adenovector CD40 ligand immunotherapy of canine malignant melanoma. J Immunother. 2008;31(4):377-384.

50. Westberg S, Sadeghi A, Svensson E, et al. Treatment efficacy and immune stimulation by AdCD40L gene therapy of spontaneous canine malignant melanoma. J Immunother. 2013;36(6):350-358.

51. Górski J, Mizak B, Chrobocińska M. Control of rabbit myxomatosis in Poland. Rev Sci Tech. 1994;13(3):869-879.

52. Smith BF, Curiel DT, Ternovoi VV, et al. Administration of a conditionally replicative oncolytic canine adenovirus in normal dogs. Cancer Biother Radiopharm. 2006;21(6):601-606.

53. LeBlanc AK, Naik S, Galyon GD, et al. Safety studies on intravenous administration of oncolytic recombinant vesicular stomatitis virus in purpose-bred beagle dogs. Hum Gene Ther Clin Dev. 2013;24(4): 174-181.

54. Bull LB, Dickinson CG. The specificity of the virus of rabbit myxomatosis. J Counc Sci Ind Res. 1937;10:291-294.

55. Freytag SO, Barton KN, Brown SL, et al. Replication-competent adenovirus-mediated suicide gene therapy with radiation in a preclinical model of pancreatic cancer. Mol Ther. 2007;15(9):1600-1606.

56. Lu Y, Zhang Y, Chang G, Zhang J. Comparison of prostate-specific promoters and the use of PSP-driven virotherapy for prostate cancer. Biomed Res Int. 2013;2013:624632.

57. Autio KPM, Ruotsalainen JJ, Anttila MO, et al. Attenuated Semliki Forest virus for cancer treatment in dogs: safety assessment in two laboratory Beagles. BMC Veterinary Research. 2015;11:170.

58. Smith GL, Vanderplasschen A, Law M. The formation and function of extracellular enveloped vaccinia virus. J Gen Virol. 2002;83:2915-2931.

59. Kaufman HL, Flanagan K, Lee CS, Perretta DJ, Horig H. Insertion of interleukin-2 (IL-2) and interleukin-12 (IL-12) genes into vaccinia virus results in effective anti-tumor responses without toxicity. Vaccine. 2002;20(13-14):1862-1869.

60. Karupiah G, Coupar BE, Andrew ME, et al. Elevated natural killer cell responses in mice infected with recombinant vaccinia virus encoding murine IL-2. J Immunol. 1990;144:290-298.

61. Selin LK, Santolucito PA, Pinto AK, Szomolanyi-Tsuda E, Welsh RM. Innate immunity to viruses: control of vaccinia virus infection by gamma delta T cells. J Immunol. 2001;166(11):6784-6794.

62. Xu R, Johnson AJ, Liggitt D, Bevan MJ. Cellular and humoral immunity against vaccinia virus infection of mice. J Immunol. 2004;172(10):6265-6271

63. Chaudhri G, Panchanathan V, Buller RM, et al. Polarized type 1 cytokine response and cell-mediated immunity determine genetic resistance to mousepox. Proc Natl Acad Sci U S A. 2004;101(24): 9057-9062.

64. Buller RM, Smith GL, Cremer K, Notkins AL, Moss B. Decreased virulence of recombinant vaccinia virus expression vectors is associated with a thymidine kinase-negative phenotype. Nature. 1985;317(6040):813-815 
65. Gnant MF, Noll LA, Irvine KR, et al. Tumor-specific gene delivery using recombinant vaccinia virus in a rabbit model of liver metastases. J Natl Cancer Inst. 1999;91(20):1744-1750.

66. Gnant MF, Puhlmann M, Alexander HR Jr, Bartlett DL. Systemic administration of a recombinant vaccinia virus expressing the cytosine deaminase gene and subsequent treatment with 5-fluorocytosine leads to tumor-specific gene expression and prolongation of survival in mice. Cancer Res. 1999;59(14):3396-3403.

67. Kudo-Saito C, Hodge JW, Kwak H, Kim-Schulze S, Schlom J, Kaufman HL. 4-1BB ligand enhances tumor-specific immunity of poxvirus vaccines. Vaccine. 2006;24(23):4975-4986.

68. Adelfinger M, Bessler S, Frentzen A, et al. Preclinical testing oncolytic vaccinia virus strain GLV-5b451 expressing an anti-VEGF single-chain antibody for canine cancer therapy. Viruses. 2015; 7:4075-4092.

69. Wang LC, Lynn RC, Cheng G, et al. Treating tumors with a vaccinia virus expressing IFN $\beta$ illustrates the complex relationships between oncolytic ability and immunogenicity. Mol Ther. 2012;20(4):736-748.

70. Huang B, Sikorski R, Kirn DH, Thorne SH. Synergistic anti-tumor effects between oncolytic vaccinia virus and paclitaxel are mediated by the IFN response and HMGB1. Gene Ther. 2011;18(2):164-172.

71. Andrewes $\mathrm{CH}$, Harisijades $\mathrm{S}$. Propagation of myxoma virus in one-day old mice. Br J Exp Pathol. 1955;36(1):18-21.

72. Fenner F, Woodroofe GM. The pathogenesis of infectious myxomatosis; the mechanism of infection and the immunological response in the European rabbit (Oryctolagus cuniculus). Br J Exp Pathol. 1953; 34:400-411.

73. Fenner F. Adventures with poxviruses of vertebrates. FEMS Microbiol Rev. 2000;24:123-133.

74. Jackson EW, Dorn CR, Saito JK, McKercher DG. Absence of serological evidence of myxoma virus infection in humans exposed during an outbreak of myxomatosis. Nature. 1966;211:313-314.

75. McCabe VJ, Spibey N. Potential for broad-spectrum protection against feline calicivirus using an attenuated myxoma virus expressing a chimeric FCV capsid protein. Vaccine. 2005;23(46-47):5380-5388.

76. McCabe VJ, Tarpey I, Spibey N. Vaccination of cats with an attenuated recombinant myxoma virus expressing feline calicivirus capsid protein. Vaccine. 2002;20(19-20):2454-2462.

77. Pignolet B, Boullier S, Gelfi J, et al. Safety and immunogenicity of myxoma virus as a new viral vector for small ruminants. J Gen Virol. 2008;89(Pt 6):1371-1379.

78. MacNeill AL, Moldenhauer T, Doty R, Mann T. Myxoma virus induces apoptosis in cultured feline carcinoma cells. Res Vet Sci. 2012;93(2):1036-1038.
79. Sypula J, Wang F, Ma Y, Bell J, McFadden G. Myxoma virus tropism in human tumor cells. Gene Ther Mol Biol. 2004;8:103-114.

80. Wang F, Ma Y, Barrett JW, et al. Disruption of Erk-dependent type I interferon induction breaks the myxoma virus species barrier. Nat Immunol. 2004;5(12):1266-1274.

81. Woo Y, Kelly KJ, Stanford MM, et al. Myxoma virus is oncolytic for human pancreatic adenocarcinoma cells. Ann Surg Oncol. 2008; 15(8):2329-2335.

82. Lun X, Yang W, Alain T, et al. Myxoma virus is a novel oncolytic virus with significant antitumor activity against experimental human gliomas Cancer Res. 2005;65(21):9982-9990.

83. Lun XQ, Zhou H, Alain T, et al. Targeting human medulloblastoma: oncolytic virotherapy with myxoma virus is enhanced by rapamycin. Cancer Res. 2007;67(18):8818-8827.

84. Lun X, Alain T, Zemp FJ, et al. Myxoma virus virotherapy for glioma in immunocompetent animal models: optimizing administration routes and synergy with rapamycin. Cancer Res. 2010;70(2):598-608.

85. Stanford MM, Shaban M, Barrett JW, et al. Myxoma virus oncolysis of primary and metastatic B16F10 mouse tumors in vivo. Mol Ther. 2008;16(1):52-59.

86. Thomas DL, Doty R, Tosic V, et al. Myxoma virus combined with rapamycin treatment enhances adoptive $\mathrm{T}$ cell therapy for murine melanoma brain tumors. Cancer Immunol Immunother. 2011;60(10): 1461-1472.

87. Doty RA, Liu J, McFadden G, Roy EJ, MacNeill AL. Histological evaluation of intratumoral myxoma virus treatment in an immunocompetent mouse model of melanoma. Oncolytic Virother. 2013;2:1-17.

88. Tosic V, Thomas DL, Kranz DM, et al. Myxoma virus expressing a fusion protein of interleukin-15 (IL15) and IL15 receptor alpha has enhanced antitumor activity. PLoS One. 2014;9(10):e109801.

89. Kim M, Rahman MM, Cogle CR, McFadden G. Prevention of EBV lymphoma development by oncolytic myxoma virus in a murine xenograft model of post-transplant lymphoproliferative disease. Biochem Biophys Res Commun. 2015;462(4):283-287.

90. Reagan RL, Strand N, Brueckner AL. Bwamba fever virus and Semliki Forest virus in young dogs. Proc Soc Exp Biol Med. 1953;82(4):642-643.
Oncolytic Virotherapy

\section{Publish your work in this journal}

Oncolytic Virotherapy is an international, peer-reviewed, open access online journal publishing original research, study protocols, reviews, editorials and commentaries on all aspects of oncolytic virology, namely the application of oncolytic viruses for the treatment of cancer. Specific topics in the journal include: Rationale and theoretical aspects of oncolytic virotherapy including in vitro, in vivo and mathematical

Submit your manuscript here: http://www.dovepress.com/oncolytic-virotherapy-journal

\section{Dovepress}

modeling; and practical application and problem solving in the clinic including identification of potential responders through biomarkers and genetic profiling. The manuscript management system is completely online and includes a very quick and fair peer-review system, which is all easy to use. Visit http://www.dovepress.com/ testimonials.php to read real quotes from published authors. 